\title{
QUALIDADE DA ESTRUTURA DO SOLO EM SISTEMA INTEGRADO DE PRODUÇÃO AGROPECUÁRIA NO MUNICÍPIO DE ARIQUEMES, RONDÔNIA
}

\author{
Lucas Pedro Cipriani'; Julyana Corrêa de Ávila²; Rogério Carlos de Souza33; Edneia Maria Sobrinho \\ Rodrigues ${ }^{4}$; Edimar Rodrigues Soares ${ }^{5}$; Adriana Ema Nogueira ${ }^{6}$.

\footnotetext{
${ }^{1}$ Faculdade de Educação e Meio Ambiente, Ariquemes, Rondônia, Brasil, lucas04pedro@hotmail.com ${ }^{2}$ Faculdade de Educação e Meio Ambiente, Ariquemes, Rondônia, Brasil, implemaq.rogerio@gmail.com ${ }^{3}$ Faculdade de Educação e Meio Ambiente, Ariquemes, Rondônia, Brasil, julyy_avila@hotmail.com

${ }^{4}$ Faculdade de Educação e Meio Ambiente, Ariquemes, Rondônia, Brasil, neia-jonas@hotmail.com

${ }^{5}$ Faculdade de Educação e Meio Ambiente, Ariquemes, Rondônia, Brasil, soares-agro@htmail.com

6Faculdade de Educação e Meio Ambiente, Ariquemes, Rondônia, Brasil, agronomia@faema.edu.br
}

RESUMO: Objetivou-se avaliar a qualidade da estrutura do solo, em um sistema integrado de produção agropecuária. O estudo foi realizado na fazenda Esperança, no município de Ariquemes-RO, em agosto de 2017. Foram amostradas três áreas pertencentes ao sistema integrado de produção e uma área de pastagem extensiva. A área 1 apresenta antecedentes de cultivo em sucessão de milho/ Brachiaria ruziziensis (sem pastejo) no ano agrícola 2015/2016 e uma safra de soja em 2016/2017. Na área 2 anteriormente ocorreu o cultivo em sucessão de soja/milho/Brachiaria ruziziensis (com pastejo) no ano agrícola 2014/2015 com 1 safra de soja em 2015/2016 e novamente soja em 2016/2017. A área 3 é proveniente de sucessão Brachiaria ruziziensis/soja (sem pastejo) no ano agrícola de 2014/2015, seguida de 1 safra de soja em 2015/2016 e novamente soja/Brachiaria ruziziensis em 2016/2017. A área 4, era constituída de uma pastagem degradada. Avaliou-se a qualidade da estrutura do solo visualmente, pelo método de diagnóstico rápido da estrutura do solo, atribuindo notas de 1 a 6 para o Índice de qualidade estrutural do solo (IQES). Os manejos empregados nas áreas 1, 2 e 3 proporcionaram a obtenção de qualidade estrutural do solo superior a da área 4 (área de pastagem degradada), sendo observadas as seguintes notas 4,87; 4,67; 5,67 e 2,57, para as áreas 1, 2, 3 e 4, respectivamente. A Sucessão Brachiaria ruziziensis/soja (sem pastejo), soja, soja/Brachiaria ruziziensis resultou em melhor qualidade da estrutura do solo. A pastagem degradada apresentou qualidade da estrutura do solo ruim.

PALAVRAS-CHAVE: Estrutura do solo, Manejo do solo, Plantio direto. 


\title{
SOIL STRUCTURE QUALITY IN AN INTEGRATED AGRICULTURAL PRODUCTION SYSTEM IN THE MUNICIPALITY OF ARIQUEMES, RONDÔNIA
}

\begin{abstract}
The objective was to evaluate the quality of soil structure in an integrated system of agricultural production. The study was carried out at the farm Esperança, in the municipality of Ariquemes-RO, in August 2017. Three areas belonging to the integrated production system and an extensive pasture area were sampled. Area 1 shows a history of cultivation in succession of corn / Brachiaria ruziziensis (without grazing) in the agricultural year 2015/2016 and a soybean crop in 2016/2017. In area 2, soybean / maize / Brachiaria ruziziensis (grazing) succession in the agricultural year 2014/2015 with 1 soybean crop in 2015/2016 and soybeans in 2016/2017 occurred previously. Area 3 comes from Brachiaria ruziziensis / soybean succession (without grazing) in the agricultural year 2014/2015, followed by 1 soybean crop in 2015/2016 and again soybean / Brachiaria ruziziensis in 2016/2017. Area 4 was composed of degraded pasture. The quality of the soil structure was evaluated visually by the rapid soil structure diagnosis method, assigning scores from 1 to 6 for the Soil Structural Quality Index (IQES). The treatments used in areas 1, 2 and 3 provided higher soil structural quality than area 4 (degraded pasture area), with the following notes being observed: 4.87; 4.67; 5.67 and 2.57, for areas 1, 2, 3 and 4, respectively. The succession Brachiaria ruziziensis / soybean (without grazing), soybean, soybean / Brachiaria ruziziensis resulted in better quality of soil structure. The degraded pasture presented bad soil structure quality.
\end{abstract}

KEYWORDS: No-till; Soil management, Soil structure.

\section{CALIDAD DE LA ESTRUCTURA DEL SUELO EN SISTEMA INTEGRADO DE PRODUCCIÓN AGROPECUARIA EN EL MUNICIPIO DE ARIQUEMES, RODONIA}

RESUMEN: Se objetivó evaluar la calidad de la estructura del suelo, en un sistema integrado de producción agropecuaria. El estudio fue realizado en la hacienda Esperanza, en el municipio de Ariquemes-RO, en agosto de 2017. Se muestrearon tres áreas pertenecientes al sistema integrado de producción y un área de pastoreo extensiva. El área 1 presenta antecedentes de cultivo en sucesión de maíz / Brachiaria ruziziensis (sin pastoreo) en el año agrícola 2015/2016 y una cosecha de soja en 2016/2017. En el área 2 anteriormente ocurrió el cultivo en sucesión de soja / maíz / Brachiaria ruziziensis (con pastoreo) en el año agrícola 2014/2015 con 1 za de soja en 2015/2016 y nuevamente soja en 2016/2017. El área 3 procede de sucesión Brachiaria ruziziensis / soja (sin pastoreo) en el año agrícola de 2014/2015, seguida 
de 1 za de soja en 2015/2016 y nuevamente soja / Brachiaria ruziziensis en 2016/2017. El área 4, estaba constituida de un pastoreo degradado. Se evaluó la calidad de la estructura del suelo visualmente, por el método de diagnóstico rápido de la estructura del suelo, asignando notas de 1 a 6 para el Índice de calidad estructural del suelo (IQES). Los manejos empleados en las áreas 1, 2 y 3 proporcionaron la obtención de calidad estructural del suelo superior a la del área 4 (área de pastoreo degradada), observándose las siguientes notas 4,87; 4,67; 5,67 y 2,57, para las áreas 1, 2, 3 y 4, respectivamente. La sucesión Brachiaria ruziziensis / soja (sin pastoreo), soja, soja / Brachiaria ruziziensis resultó en mejor calidad de la estructura del suelo. El pastoreo degradado presentó calidad de la estructura del suelo malo.

PALABRAS CLAVE: Estructura del suelo, Manejo del suelo, Planto directo.

Nas últimas décadas, o Brasil se consolidou como grande potência na produção de alimentos (RALICH et al., 2017). O agronegócio é um setor de destaque, estando em ascensão a cada ano. Em 2016, o agronegócio contribuiu com a participação de 23\% no Produto Interno Bruto (PIB). A pecuária é uma das atividades que mais se destaca no país, tendo contribuído em $2015 \quad 30 \%$ do agronegócio brasileiro. Esse fato se deve ao incremento de tecnologias no campo visando o ganho de produtividade (CNA, 2016). Uma destas tecnologias é a produção alternada de grãos e de pastejo animal em uma mesma área introduzindo assim a rotação de culturas, promovendo ciclagem de nutrientes no solo e diversificando a produção, contribuindo a sustentabilidade econômica e ambiental da propriedade (BALBINOTJUNIOR et al., 2009; KUNZ et al., 2013).

Devido a isso, a maior parte das áreas de pastagens, no Brasil, encontra-se em algum grau de degradação (DIAS-FILHO, 2014). O manejo incorreto do solo e a monocultura promovem a erosão e degradação de grandes áreas produtivas no território brasileiro, havendo perda de desempenho produtivo. Entre os fatores que acentuam a degradação do solo, está 
a compactação, lixiviação de nutrientes e ausência de matéria orgânica no solo (PORTELA et al, 2010).

A implantação da lavoura em áreas anteriormente ocupadas por pastagens é uma alternativa para os pecuaristas para recuperação das mesmas. A utilização de um manejo conservacionista, com utilização de plantio direto e rotação de culturas, geralmente promove melhorias das condições químicas e físicas do solo, contribuindo principalmente para a recuperação de sua estrutura, resultando no aumento da produtividade das culturas (LOPS et al., 2015; VILELA et al., 2011)

Os impactos na estrutura do solo expressam claramente os efeitos antrópicos sofridos pelo mesmo, de forma que, dependendo destes efeitos pode-se contribuir para a conservação do solo ou para sua degradação do solo. As mudanças na estrutura impactam não só a parte física, mas também as suas características químicas e biológicas (RALISCH et al, 2017).

De acordo com Macedo (2009,) as forrageiras do gênero Brachiairia spp. e Panicum spp. apresentam a capacidade de reestruturar o solo, devido ao desenvolvimento do sistema radicular e o fornecimento de palhada, a qual irá se agregar com o solo. Para Seidel et al. (2015), o consórcio de milho e Brachiaria ruziziensis promoveu o incremento de 40\% na massa seca total depositada sobre o solo, comparada com a cultura solteira.

Na região de Ariquemes alguns produtores têm adotado tecnologia de produção integrada. Nesse sentido, a utilização de métodos que avaliam de forma rápida e visualmente a estrutura do solo podem contribuir para a conservação do solo e, portanto, para o sucesso dos sistemas de produção. Nesse contexto, objetivou-se com este trabalho avaliar a qualidade estrutural do solo, em função do manejo em um sistema integrado de produção agropecuária 
no município de Ariquemes,

A pesquisa foi conduzida na fazenda Esperança, localizada na gleba 45, linha 75, lote 48 na zona rural do município de Ariquemes, latitude $9^{\circ} 55^{\prime} 12^{\prime \prime} \mathrm{S}$, longitude de $62^{\circ}$ 55'59" $\mathrm{O}$ e latitude $128 \mathrm{~m}$ de altura. $\mathrm{O}$ clima da região é classificado como grupo tropical chuvoso (tipo Aw) segundo köppen. O solo da área é um Latossolo Vermelho-Amarelo distrófico (RONDÔNIA, 2012).

Foram amostradas em agosto de 2017 três áreas pertencentes ao sistema integrado de produção e uma área de pastagem extensiva. A área 1 apresenta antecedentes de cultivo em sucessão de milho/ Brachiaria ruziziensis (sem pastejo) no ano agrícola 2015/2016 e uma safra de soja em 2016/2017. Na área 2 anteriormente ocorreu o cultivo em sucessão de soja/milho/Brachiaria ruziziensis (com pastejo) no ano agrícola 2014/2015 com 1 safra de soja em 2015/2016 e novamente soja em 2016/2017. A área 3 é proveniente de sucessão Brachiaria ruziziensis/soja
Rondônia.

(sem pastejo) no ano agrícola de 2014/2015, seguida de 1 safra de soja em 2015/2016 e novamente soja/Brachiaria ruziziensis em 2016/2017. A área 4, era constituída de uma pastagem degradada e presença considerável de plantas daninhas.

Para a avaliação visual da estrutura do solo, utilizou-se a metodologia proposta por Ralich et al. (2017), selecionando 3 pontos representativos e aleatórios por área de manejo. Com auxílio de pá reta e enxadão foram abertas mini-tricheiras, ás quais foram retirados um bloco de $20 \mathrm{~cm}$ de comprimento $\times 25 \mathrm{~cm}$ de profundidade $\times 10 \mathrm{~cm}$ de largura. Em seguida, o bloco foi cuidadosamente depositado em uma bandeja plástica com $25 \mathrm{~cm}$ de largura, $50 \mathrm{~cm}$ de comprimento e $15 \mathrm{~cm}$ de altura. $\mathrm{Na}$ sequência procedeu-se a fragmentação do bloco de solo em torrões ou agregados de menor tamanho, tomando-se o cuidado de identificar as diferentes camadas nas amostras. 
De acordo com a metodologia de Ralich et al. (2017), foram feitas a atribuições de notas à qualidade estrutural de cada camada (Qec) detectada na amostra. Estas notas serviram de base para o cálculo e definição da qualidade estrutural dessa amostra (IQEA).

Para a atribuição das notas levouse em conta dois critérios, sendo o primeiro, evidências de degradação (compactação ou desagregação) ou conservação/recuperação do solo; e o segundo, a proporção visual da ocorrência (em volume) dos diferentes tamanhos de agregados após a manipulação da amostra, segundo a chave de atribuição das notas. As notas foram baseadas em uma pontuação crescente (Qec 1 a Qec 6), variando em função das evidencias de compactação ou degradação.

Após a identificação das camadas, obtenção da espessura e atribuição de notas para cada camada (Qec), calculou-se o Índice de Qualidade Estrutural do solo da Amostra (IQEA), por meio da equação (1):

$$
I Q E A=\frac{(\mathrm{Ec} 1 \times \mathrm{Qec} 1)+(\mathrm{Ec} 2 \times \mathrm{Qec} 2)+(\mathrm{Bc} 1 \times \mathrm{Qec} 3)}{\text { Etotal }}
$$

Onde: IQEA) índice de qualidade estrutural do solo da amostra; Ec) espessura de cada camada, em cm (o número de camadas pode variar de 1 a 3); Qec) nota de qualidade estrutural atribuída à cada camada; Etotal) espessura/profundidade total da amostra $(25 \mathrm{~cm})$. Com a média das três amostras tem-se o Índice de qualidade estrutural do solo (IQES).

Com os dados obtidos, procedeuse a análise estatística, sendo realizada a análise de variância e posterior separação de médias pelo teste de Tukey, a 5\% de probabilidade.

Na Tabela 1 são apresentados os valores de IQEA, de IQES e o resumo da análise de variância para as diferentes áreas estudadas. Observase que os manejos empregados nas áreas 1, 2 e 3 proporcionaram a obtenção de qualidade estrutural do solo superior à da área 4 (área de pastagem degradada). 
Tabela 1. Índice de qualidade estrutural do solo em função do manejo em sistema de produção integrado no município de Ariquemes-RO.

\begin{tabular}{ccclc}
\hline \multicolumn{1}{c}{ Área } & IQEA & IQES (média) \\
\hline Área 1 & 5,64 & 3,97 & 5,0 & $4,87 \mathrm{a}$ \\
Área 2 & 5,0 & 4,5 & 4,52 & $4,67 \mathrm{a}$ \\
Área 3 & 6,0 & 6,0 & 5,0 & $5,67 \mathrm{a}$ \\
Área 4 & 3,0 & 2,0 & 2,72 & $2,57 \mathrm{~b}$ \\
\hline
\end{tabular}

*Médias seguidas pela mesma letra não se diferem estatisticamente pelo teste de Tukey a $5 \%$ de probabilidade.

A faixa de IQES de 4,0 a 4,9, na qual se encaixam as notas obtidas com os manejos empregados nas áreas 1 e 2 (Tabela 1), indica uma qualidade da estrutura do solo boa, segundo Ralich et al. (2017). Para esse nível de qualidade estrutural, os autores indicam intensificar o uso de sistemas diversificados de produção com alta capacidade de aporte de fitomassa aérea e raízes, verificando a necessidade de interferir na estratégia de rotação e consorciação de culturas adotada no sistema de produção.

No Tabela 1, observa-se que a pastagem degradada (área 4), apresentou qualidade estrutural do solo classificada como ruim (faixa de 2,0 a 2,9). As baixas notas obtidas para a qualidade da estrutura do solo nesse manejo se deve principalmente à elevada desagregação do solo observada nesta área. De acordo com Ralich et al. (2017), para estruturas de solo ruins é necessário rever e aprimorar o sistema de produção, aumentando a diversidade de espécies vegetais, priorizando culturas com alta capacidade de aporte de fitomassa aérea e raízes.

Diversas pesquisas evidenciam a contribuição da matéria orgânica formação e estabilização dos agregados do solo (MULUMBA; LAL, 2008; NOELLEMEYER et al., 2008; ANDERS et al., 2010; FERNANDEZ et al., 2010; HUANG et al., 2010). Em áreas degradadas, há estacionalidade da produção das forrageiras, de forma que o sistema radicular também é comprometido, fato que colabora para a desagregação do solo. 
A melhor qualidade estrutural do solo foi observada no manejo empregado na área 3, enquadrandose na faixa de 5,0 a 6,0, ou seja, qualidade estrutural muito boa. Nesta área foi realizado sucessão de Brachiaria ruziziensis/soja. Estes resultados demonstram o potencial desta gramínea para utilização em recuperação de áreas degradadas e melhoria das condições estruturais do solo. Pela Figura 1, pode-se observar qualidade da estrutura do solo na área três, apresentando entre 1 a 4 cm, com características de grumosidade e raízes distribuídas em todo perfil. Todos estes fatores são características de conservação do solo.

As Brachiarias são amplamente usadas para a formação de palhada, devido á sua alta relação $\mathrm{C} / \mathrm{N}$ e composição de ligninina prolongando a decomposição do mesmo no solo (NEPOMUCENO et al, 2012). De acordo com Castro-Filho, Muzilli e Podanoschi (2017) estas gramíneas contribuem para o acúmulo de resíduos vegetais na camada de 0-10 cm de profundidade, proporcionando melhores índices de agregação do solo. Brandão e Silva (2012) concluíram que o sistema radicular da Brachiaria ruziziensis favorece maior formação e estabilização dos agregados no solo.

Em sua pesquisa, Gomes e Correa (2015) comprovaram a eficiência dessa pastagem para produção de palhada e supressão de daninhas, apresentando-se como excelente gramínea para utilização em sistemas de plantio direto, ou seja, em manejos que promovam a recuperação e a conservação do solo.

Na Figura 2, observa-se ótima cobertura do solo e alta concentração de palhada de Brachiaria ruziziensis, dessecada para palntio de soja na área 3, no momento da avalição da estrutura. 
Figura 1. Estrutura do solo na camada de $25 \mathrm{~cm}$, com manejo de sucessão Brachiaria ruziziensis/soja/Brachiaria ruziziensis (sem pastejo).

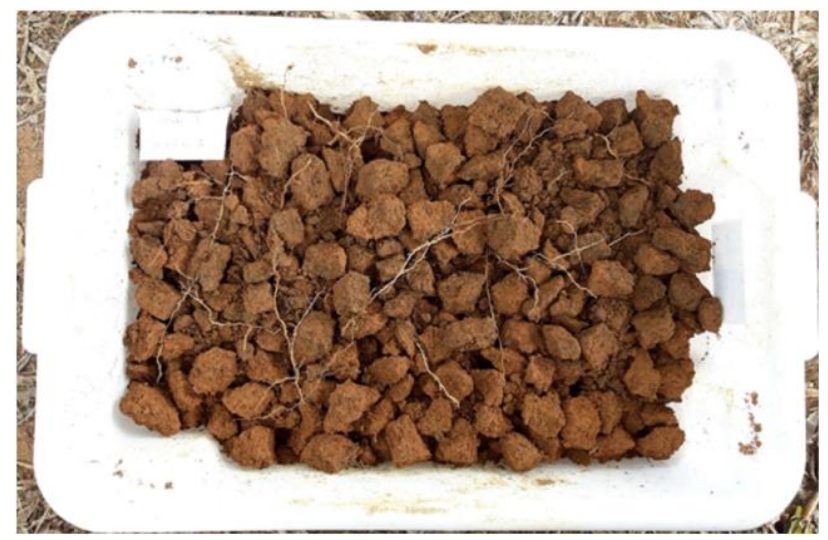

Figura 2. Palhada de Brachiaria ruziziensis na área 3, após dessecaçaõ, em preparo para plantio direto de soja.

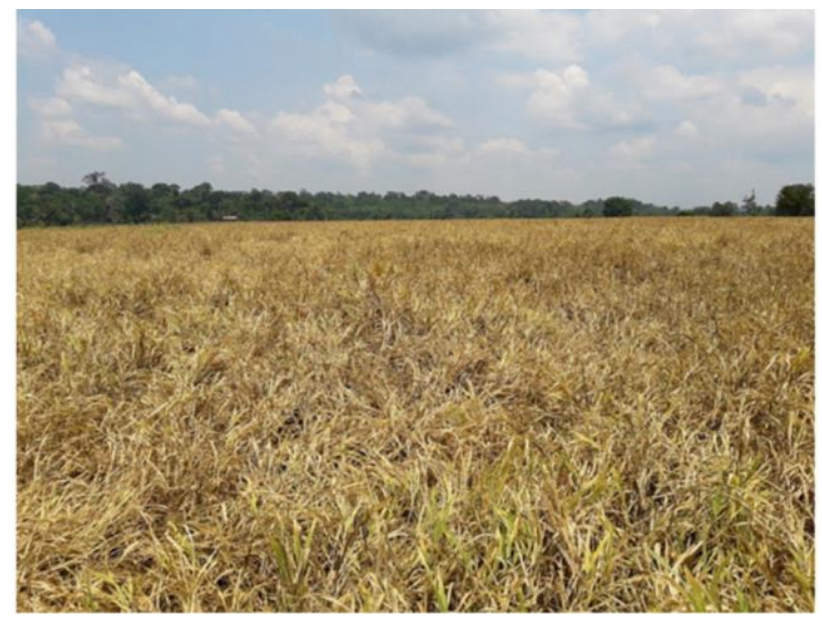

O diagnóstico rápido da estrutura do solo demonstra ser uma eficiente ferramenta para ser utilizada em sistemas integrados de produção agropecuária. De fácil aplicação, esta metodologia auxilia o produtor no monitoramento da qualidade estrutural do solo e na tomada de decisão, alertando quanto aos sinais de compactação, para que se possa fazer alteraç̃̃es no manejo adotado.

A sucessão Brachiaria ruziziensis/soja (sem pastejo), soja, soja/Brachiaria ruziziensis resultou em melhor qualidade da estrutura do solo. A pastagem degradada apresentou qualidade da estrutura do solo ruim. 


\section{REFERÊNCIAS}

ANDERS, M. M.; BECK, P. A.; WATKINS, B. K.; GUNTER, S. A.; LUSBY, K. S.; HUBBELL, D. S. Soil aggregates and their associated carbon and nitrogen content in winter annual pastures. Soil and Water Management and Conservation, v. 74, p. 1339-1347, 2010.

BALBINOT-JUNIOR, A. A.; MORAES, A.; VEIGA, M.; PELISSARI, A.; DIECKOW, J. Integração lavourapecuária: intensificação de uso de áreas agrícolas. Ciência Rural, v. 39, n. 6, p. 1925-1933, 2009.

BRANDAO, E. D.; SILVA, I. de F. da. Formação e estabilização de agregados pelo sistema radicular de braquiária em um Nitossolo Vermelho. Ciencia Rural, v. 42, n. 7, p. 1193-1199, 2012.

CNA. PIB e Performance do Agronegócio. p.21. 2017.

CORREIA, N. M; GOMES, L. J. P. Sobressemeadura de soja com Urochloa ruziziensis e a cultura do milho em rotação. Pesquisa Agropecuária Brasileira, v.50, n. 11, p. 1017-1026, 2015.

DIAS-FILHO, M. B. Diagnóstico das pastagens no Brasil. Belém: Embrapa Amazônia Oriental, 2014. 36 p.

FERNÁNDEZ, R.; QUIROGA, A.; ZORATI, C.; NOELLEMEYER, E. Carbon contents and respiration rates of aggregate size fractions under no-till and conventional tillage. Soil and
Tillage Research, v. 109, n. 2, p. 103109, 2010.

HUANG, L.; WANG, C. Y.; TAN, W. F.; HU, H. Q.; CAI, C. F.; WANG, M. K. Distribution of organic matter in aggregates of eroded Ultisols, Central China. Soil and Tillage Research, v. 108, n. 2, p. 59-67, 2010.

KUNZ, M.; GONÇALVES, A. D. M. de A.; REICHERT, J. M.; GUIMARÃES, R. M. L.; REICHERT, D. J.; RODRIGUES, M. F. Compactação do solo na integração soja-pecuária de leite em Latossolo argiloso com semeadura direta e escarificação. Revista

Brasileira

Ciências do Solo, v. 37, n. 6, p. 16991708, 2013.

LOPES, A. S; WIETHOLTER, S; GUILHERME, L. R. G; SILVA, C. A. Sistema plantio direto: bases para o manejo da fertilidade do solo. São Paulo: ANDA, 2015. 115 p.

MACEDO, M. C. M. Integração lavoura-pecuária: o estado da arte e inovações tecnológicas. Revista Brasileira de zootecnia, v. 38, n. 1, p. 133-146, 2009.

MULUMBA, L. N.; LAL, R. Mulching effects on select soil properties. Soil and Tillage Research, v. 98, n. 1, p. 106-111, 2008.

NEPOMUCENO, M.P; VARELA, R. M; ALVES, P.L.C.A; MARTINS, J.V.F. Períodos de Dessecação de Urochloa ruziziensis e seu reflexo na produtividade RR. Planta Daninha, v.30, n.3, p.557-565, 2012. 
NOELLEMEYER, E.; FRANK, F.; ALVAREZ, C.; MORAZZO, G.; QUIROGA, A. Carbon contents and aggregation related to soil physical and biological properties under a land-use sequence in the semiarid region of central Argentina. Soil and Tillage Research, v. 99, n. 2, p. 179-190, 2008.

PORTELA， J. C; COGO, N. P; BAGATINI, T; CHAGAS, J. P; PORTZ, G. Restauração da estrutura do solo por sequências culturais implantadas em semeadura direta, e sua relação com a erosão hídrica em distintas condições físicas de superfície. Revista Brasileira de Ciências do solo, v. 34, n. 4, 13531364, 2010.

RALISCH, R.; DEBIASI, H.; FRANCHINI, J. C.; TOMAZI, M.; HERNANI, L. C.; MELO, A. da S.; SANTI, A.; MARTINS, A. L. da S.; BONA, F. D. Diagnóstico Rápido da Estrutura do Solo: DRES. Londrina: Embrapa Soja, 2017. 64p.

RONDÔNIA. Secretaria do Estado do Desenvolvimento Ambiental (SEDAM).

Boletim climatológico de Rondônia, 2010. v. 12. Porto Velho: SEDAM, 2012. $34 p$.

SEIDEL, P. E.; MATTIA, V; MATTEI, E.; CORBAN, F. Produção de matéria seca e propriedades físicas do solo na consorciação milho e braquiária. Scientia Agraria, v. 14, n.1, p. 18-2, 2015.

VILELA, L.; MARTHA JÚNIOR, G. B.; MACEDO, M. C. M.; MARCHÃO, R. L.; GUIMARÃES JÚNIOR, R.; PULROLNIK, K.; MACIEL, G. A. Sistema de integração lavoura-pecuária na região do Cerrado. Pesquisa Agropecuária

Brasileira, v.46, p.1127-1138, 2011. 